\title{
Chlorpyrifos-induced Histopathological Alterations in Duttaphrynus melanostictus (Schneider 1799) Tadpoles: Evidence from Empirical Trials
}

\author{
M. G. D. K. Bandara ${ }^{1}$, M. R. Wijesinghe* ${ }^{1}$, W. D. Ratnasooriya ${ }^{1}$ and A. A. H. Priyani ${ }^{2}$ \\ ${ }^{1}$ Department of Zoology, Faculty of Science, University of Colombo, Colombo 03, Sri Lanka \\ ${ }^{2}$ Department of Pathology, Faculty of Medicine, University of Colombo, Colombo 03, Sri Lanka
}

Date Received: 29-04-2012 Date Accepted: 21-06-2012

\begin{abstract}
This paper reports the histopathological responses of the gill, liver and tail muscle tissues in tadpoles of the Asian Common Toad Duttaphrynus melanostictus (Schneider, 1799) exposed to chlorpyrifos a common organophosphorus pesticide. Tadpoles of Gosner stages 24-26 were continuously exposed to low, mid and high $\left(500,1000\right.$ and $\left.1500 \mu \mathrm{gl}^{-1}\right)$ concentrations of chlorpyrifos for two weeks. Histological alterations in the tissues of the surviving larvae were microscopically examined both at the end of the exposure period and after a week following the final exposure. Several histological alterations were noted in the gills, liver and tail muscles of the larvae exposed to $1500 \mu \mathrm{gl}^{-1}$ of chlorpyrifos. The gills of exposed larvae showed architectural distortion resulting from reduced primary and secondary gill lamellae and blood vessels, and alterations in the gill epithelium. In the liver sinusoidal congestion and dilation, cytoplasmic vacuolation and changes in hepatocytes such as hyperchromatic nuclei and nuclear fragmentation were observed. The tail muscle tissue suffered from severe atrophy and myotomal disintegration. Although histological alterations in the gill and liver tissues were noted only at the high concentration, changes in the muscle tissue i.e. muscle degeneration and atrophy, were apparent at both low and mid concentrations. The degree of damage in surviving larvae in a week following the final exposure was lower than that observed during the exposure, probably indicating recovery or resistance. The findings of the present study emphasize the need to investigate possible sublethal damage induced by pesticides in amphibians inhabiting agricultural habitats.
\end{abstract}

Key words: Chlorpyrifos, gills, histopathology, liver, muscles, tadpoles

\section{Introduction}

It is widely accepted that intensive use of pesticides has detrimental consequences on aquatic organisms found in agricultural landscapes. Amphibians are known to be particularly susceptible to the adverse effects of pesticides (Rouse et al., 1999). Studies have shown that exposure to pesticide residues may result in direct mortality of amphibian larvae, whilst at the same time causing growth impairments, delays in development, and alterations in behavior and histopathological changes in tissues (Bridges, 1997; Kamrin, 1997; Young et al., 2001; Sumanadasa et al., 2008). Histopathological responses of aquatic organisms have been used as an effective early warning tool in ecological risk assessment (Adams et al., 1996; Neskovic et al., 1996). Although a considerable amount of information is available on mortality and growth relatively few studies have focused on histopathology of organisms exposed to environmental contaminants.

*Correspondence: mayuri@zoology.cmb.ac.lk

Tel: +9471446277

ISSN 2235-9370 Print / ISSN 2235-9362 Online C2012 University of Sri Jayewardenepura 
Studies on effects of pollutants on amphibians are particularly relevant to Sri Lanka, a global amphibian hotspot harboring $2 \%$ of the world's amphibians (Pethiyagoda and Manamendra-Archchi, 2006). Several species in the island have already become extinct and many species have experienced population declines and range reductions (IUCN, 2007). The widespread application of pesticides and herbicides in the plantation sector has been implicated as a possible cause (Pethiyagoda and ManamendraArchchi, 2006). The organophosphorus pesticide, Chlorpyrifos (O,O-diethyl $O$-3,5,6-trichloro-2-pyridyl phosphorothioate), is one of the most commonly used pesticides in Sri Lanka for the control of pests in rice, but is also used for other vegetable crops such as bean, pigeon pea, coconut and potato plantations. Our broad aim was to investigate the potential toxicity of the commercially available product of chlorpyrifos on larvae of a selected amphibian species in Sri Lanka. In our first paper we provide evidence that chlorpyrifos induces significant elevations in mortality and causes retardations in growth and development in tadpoles of the Asian Common Toad Duttaphrynus melanostictus (Wijesinghe et al. 2011). In this paper we examine the potential of chlorpyrifos to induce histologial alterations in vital tissues of larvae of the same species. The study species D. melanostictus is frequently found in association with human-altered habitats such as agricultural landscapes and urban settings in Sri Lanka. In general, breeding commences with the onset of the monsoons, but breeding may occur at any time of the year. The eggs are generally laid in running water, although they may breed in tanks, temporary or permanent ponds and pools (Kirtisinghe, 1955). Tadpoles of this species are easily reared under laboratory conditions. The occurrence of this species in many other South Asian countries makes the results of the present study widely applicable.

\section{Methodology}

Tadpoles of D. melanostictus corresponding to Gosner stages 24-26 were simultaneously collected from three garden ponds in the Colombo city where no pesticides were used. A commercial formulation of chlorpyrifos (Pattas) was purchased from Harcros Company Ltd, Colombo. Because there were no recorded field levels of chlorpyrifos in Sri Lanka, selection of pesticide concentrations for the exposure trials were based on laboratory investigations conducted elsewhere (Bonfanti et al., 2004; Gallo-Delgado et al., 2006). Accordingly, low, mid and high concentrations of chlorpyrifos (500, 1000 and $\left.1500 \mu \mathrm{gl}^{-1}\right)$ were selected for the experiments. A stock solution was initially prepared and appropriate volumes were then added to glass tanks containing $2 \mathrm{~L}$ of tap water. Each tank contained 18 larvae and both treatment and control (without pesticides) tanks were maintained in triplicate. The larvae were fed daily with commercially available fish food pellets (FRF Aquatic Pet Shop, Colombo, Sri Lanka).

Experiments were carried out for three weeks (21 days) with two weeks of continuous exposure to chlorpyrifos and for a further one week after the final exposure. This period was selected because many small-scale farmers in a particular area apply pesticides to their paddy fields at different times over approximately two-to-three weeks. The streams near paddy fields would therefore receive pesticidecontaminated water via surface runoff repeatedly over this period. The half-life of chlorpyrifos in water at $\mathrm{pH} 7.0$ and $35^{\circ} \mathrm{C}$ is 12 days but increases to 35 days at $25^{\circ} \mathrm{C}$ (Miles et al., 1983). During the two weeks of exposure water was changed every three days and pesticide concentrations were renewed with each water change following Sumanadasa et al., 2008, whilst only water was renewed in the week following the final exposure.

At the end of the exposure period of two weeks and after one week following the final exposure surviving three tadpoles each from treatment and control tanks were randomly collected and fixed in Zenker fixative overnight. Larvae were dehydrated in a graded alcohol series and embedded in paraffin. Longitudinal sections of $8 \mu \mathrm{m}$ thickness were prepared using a Rotary microtome (YAMATO, Tokyo, Japan), and stained with Haematoxylin and Eosin. Slides were examined under a light microscope (Student microscope, Nikon, Tokyo, Japan) and changes were noted. Images were taken under the phase 
contrast microscope (Nikon -1001v, Tokyo, Japan). Five random locations of each section obtained from one tadpole were examined and the damage to the tissue was ranked as no damage, minor damage and severe damage. Epithelial thickness of the gill tissue was also measured using a graticule.

\section{Results}

The examination of tissue samples from gills, liver and tail muscles showed that chorpyrifos has the capacity to induce histopathological changes in all three tissues of $D$. melanostictus tadpoles at concentration of $500 \mu \mathrm{g}^{-1}$ and above. The histopathological changes in each of these tissues are as follows.

\subsection{Gill tissue}

The gill tissue of tadpoles in general consists of well-structured primary and secondary gill lamellae. This is evident in the gill tissues of the larvae not exposed to chlorpyrifos (control). However, as shown in Figure 1, continuous exposure to the pesticide for two weeks caused architectural distortion of the gill tissue of the exposed larvae. The primary and secondary gill lamella in exposed larvae were much reduced or were completely absent in certain sections of the gill arch. Where present the gill lamellae were less defined and smaller compared to that of the control larvae. The gills of the control larvae were also more compact and filled with prominent blood vessels, whereas in the gills of the treated larvae the blood vessels were noticeably reduced. Greater vesicularisation was also apparent in larvae exposed to the pesticide in comparison to that of the control larvae. Furthermore, thickening of the epithelial lining of the treated larvae was notable. The overall changes to the gills were assessed and ranked taking into consideration the magnitude of damage. All tadpoles exposed to $1500 \mu \mathrm{gl}^{-1}$ for two weeks suffered severe damage. At $1000 \mu \mathrm{gl}^{-1}$ nearly half of the larvae suffered from minor damage of the gill tissue while the remaining larvae showed no signs of damage. No damage was apparent in gill tissues of larvae exposed to the lowest concentrations. The thickness in the epithelium of the control larvae was $0.0019 \mathrm{~mm}$ whilst that of the larvae exposed to $1500 \mu \mathrm{g}^{-1}$ was $0.0046 \mathrm{~mm}(\mathrm{n}=10$ tadpoles per treatment or control). Oedematous changes were also evident in exposed tadpoles after two weeks of exposure (Figure 2). Oedema in the gill lamellae also caused epithelial sloughing and detachment in larvae exposed to chlorpyrifos.

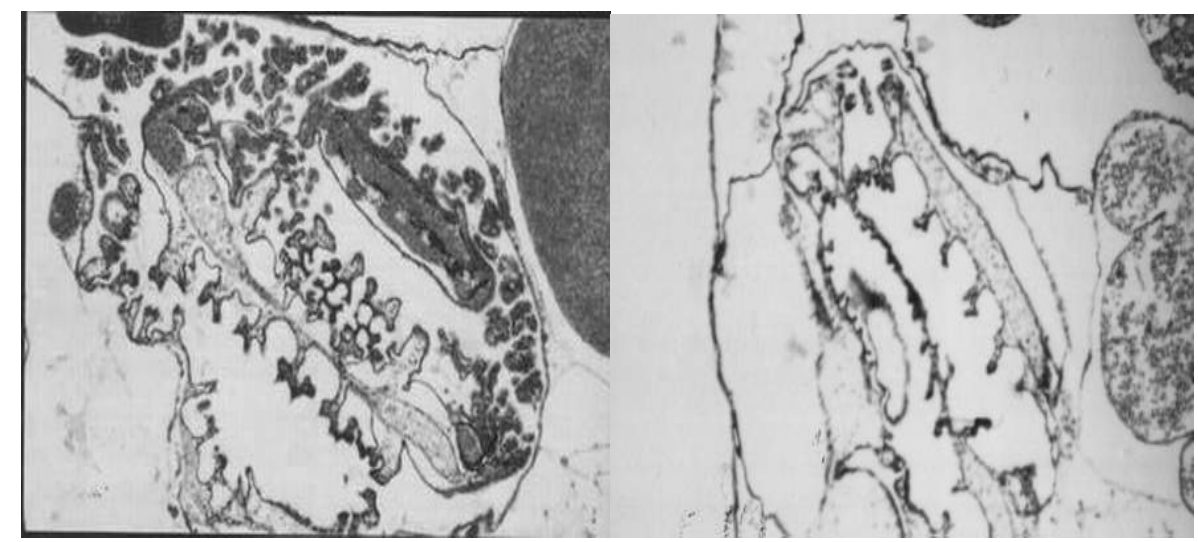

(i)

(ii)

Figure 1: Histopathological responses of the gill tissues of (i) control larvae and (ii) D. Melanostictus larvae exposed to $1500 \mu \mathrm{gl}-1$ of chlorpyrifos. Note prominent gill lamella in control larvae and reduced gill lamella in treated larvae (Magnification x100). 


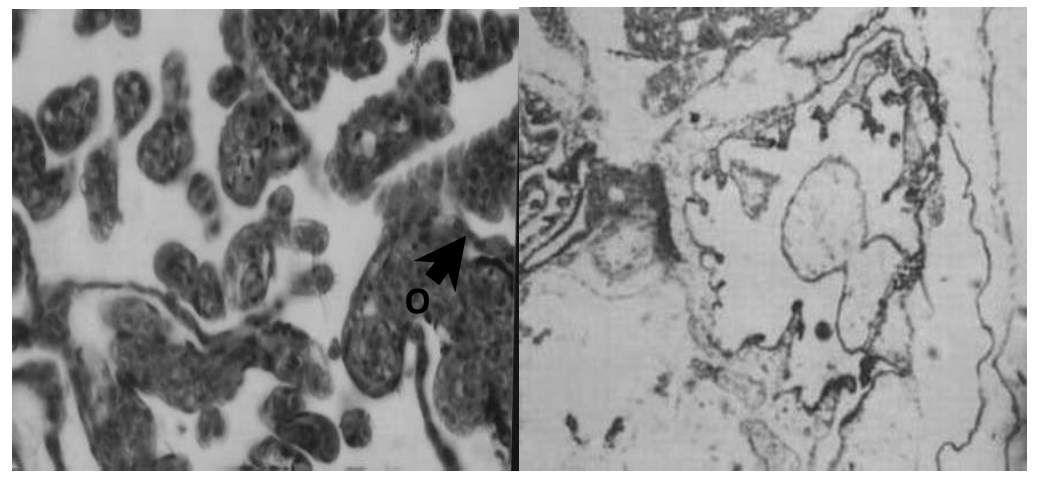

(i)

(ii)

Figure 2: Changes in the structure of the gill of $D$. melanostictus larvae (i) normal gill in control larvae and (ii) reduced gill tissue and oedema $(\mathrm{O})$ in larvae exposed to $1500 \mu \mathrm{gl}-1$ of chlorpyrifos (Magnification x 400).

A notable observation with respect to gill damage was that, larvae exposed to the highest concentration continuously for two weeks exhibited greater distortion of gill architecture than the few surviving larvae, after one week of the final exposure. After a recovery period of one week, the primary and secondary gill lamellae were more numerous than at two weeks of continuous exposure.

\subsection{Liver tissue}

The liver tissue of the larvae not exposed to pesticides exhibited the typical paranchymatous appearance, whereas the liver tissue of the treated larvae suffered loss of cellular integrity (Figure 3 ). The liver tissue of those exposed to chlorpyrifos showed sinusoidal congestion, which is the collection of an excessive amount of blood within the sinusoid (Hibiya, 1982) resulting in the dialation of the sinusoids. The hepatocytes of treated larvae had marked cytoplasmic vacuolations and enlarged hyperchromatic nuclei and displayed nuclear fragmentation (Figure 4). Cellular oedema was also evident in the tissues of exposed tadpoles.

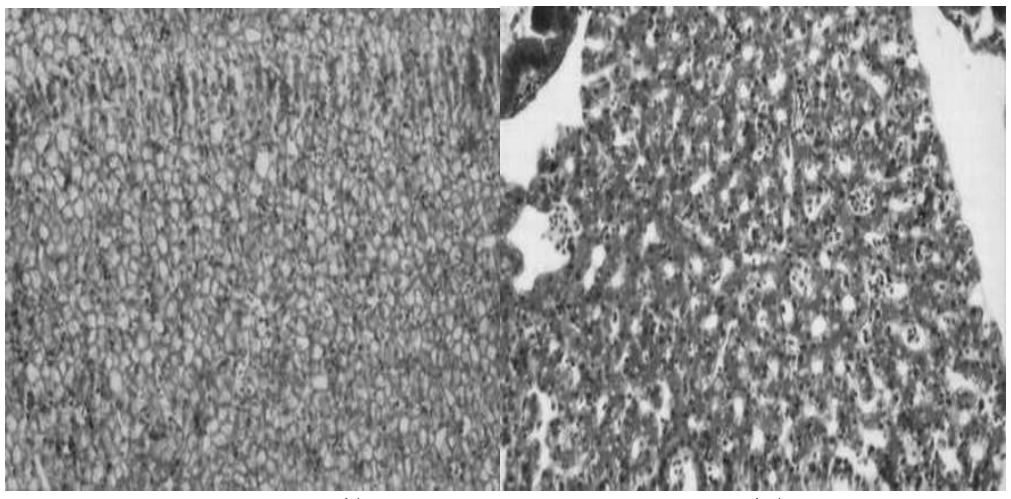

(i)

(ii)

Figure 3: Liver tissues of (i) normal D. melanostictus tadpoles and (ii) tadpoles exposed to $1500 \mu \mathrm{gl}-1$ of chlorpyrifos. Note the intercellular spaces in liver of exposed larvae (Magnification x200).

As with the gill, the overall damage of the live tissue was assessed and ranked. The liver tissue of all tadpoles exposed to $1500 \mu \mathrm{gl}^{-1}$ for two weeks suffered severe damage while those exposed to both 500 and $1000 \mathrm{\mu gl}^{-1}$ showed no signs of any damage and the liver tissue of these tadpoles were comparable in structure to those of the control. As with the gill, signs of recovery were noted in the liver tissues of the 
surviving larvae after three weeks, i.e. one week after the final exposure, with lower vacuolation and sinusoidal congestion and lesser number of hyperchromatic and fragmented nuclei as compared to that observed at the end of the two weeks of continuous exposure.

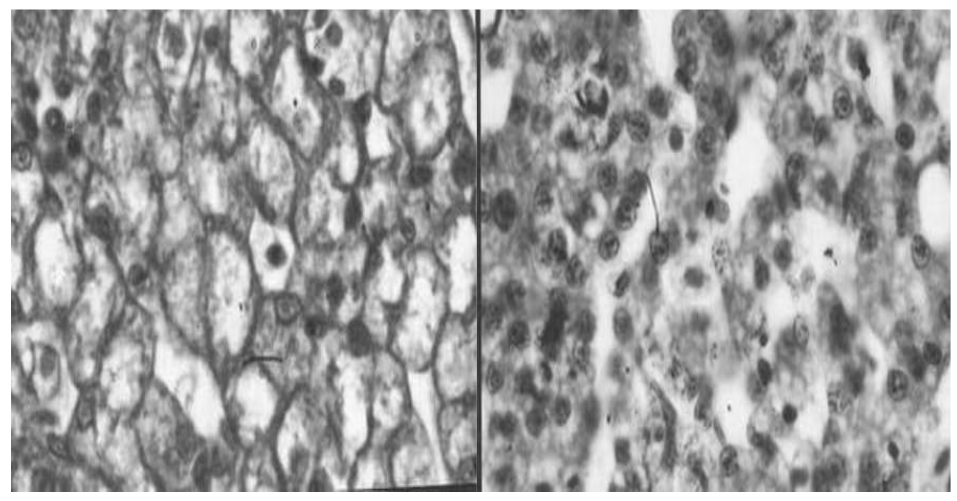

(i)

(ii)

Figure 4: Histological alterations in the liver tissues of D. melanostictus larvae induced by chlorpyrifos exposure. (i) normal hepatocytes and (ii) hapatocytes in tissues of larvae exposed to $1500 \mathrm{ugl}-1$ of chlorpyrifos showing enlarged hyperchromatic and fragmented nuclei (Magnification x1000).

\subsection{Tail muscle tissue}

It is apparent that exposure to chlorpyrifos caused excessive damage to the larval muscle tissues. In the unexposed larvae (control) lengthy myotomes were oriented in an orderly manner parallel to the notochord and were attached at regular intersomatic boundaries (Figure 5). The muscles in the control larvae were compact with few spaces in between the myotomes. In contrast, the muscle tissues of the larvae exposed to chlorpyrifos, the myotomes showed fiber atrophy, where the number and volume of cells was greatly reduced. Large myotomal spaces were also evident in the treated larvae. The degenerated muscle bundles were oriented in different directions, thus resulting in architectural distortion of the muscle tissues in the treated larvae.

In contrast to both the gill and liver tissues, a progressive increase in disintegration and distortion of myotomes were noted from 500 to $1500 \mu \mathrm{gl}^{-1}$. Considering damage to the muscle tissue, it was noted that all examined larvae showed severe damage at the highest concentration of $1500 \mu \mathrm{gl}^{-1} \mathrm{whilst}_{\text {at }} 1000$ $\mu \mathrm{gl}^{-1}$ only around $40 \%$ showed severe damage whilst the reaming proportion showed minor damage. At $500 \mathrm{\mu gl}^{-1} 75 \%$ showed minor whilst the balance $25 \%$ showed no signs of damage. Nevertheless, comparing the damage observed in the tail muscle tissue at two weeks of continuous exposure to chlorpyrifos with that a week later with no exposure, it was apparent that the damage in the latter instance was lower, a trend that was noted for both gill and liver tissues.

\section{Discussion}

Histopathological changes are considered an essential biomarker, because they indicate the levels of exposure to environmental contaminants (Rousseaux et al., 1995). The present study clearly demonstrates that the organophosphorous pesticide chlorpyrifos has the potential to induce histopathological changes in tissues of the larvae of the Asian Common Toad Duttaphrynus melanostictus. Examination of the gill, liver and muscle tissues of the larvae exposed to $1500 \mu \mathrm{gl}^{-1}$ of chlorpyrifos showed that these organs had undergone severe histological alterations while damage of a lower magnitude was noted at the mid and low concentrations. 


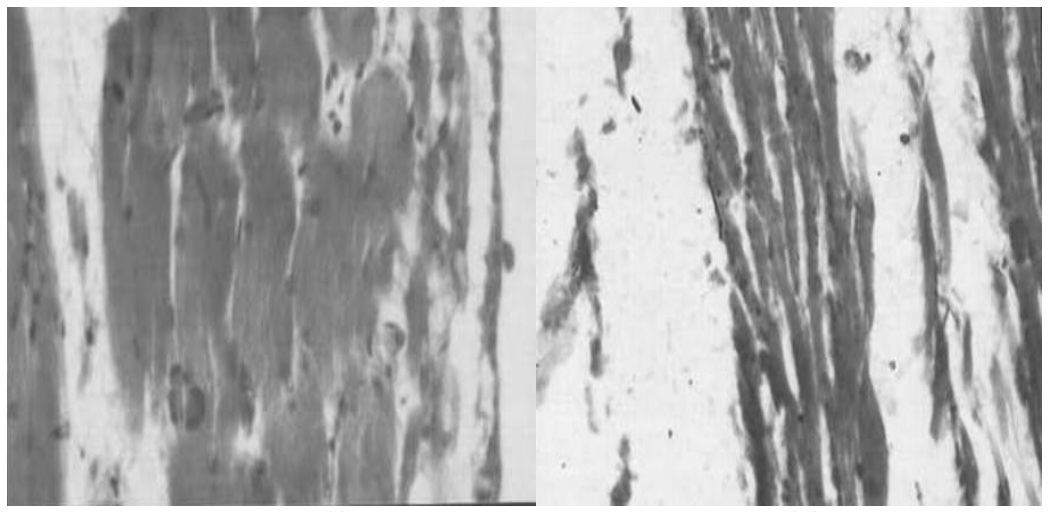

(i)

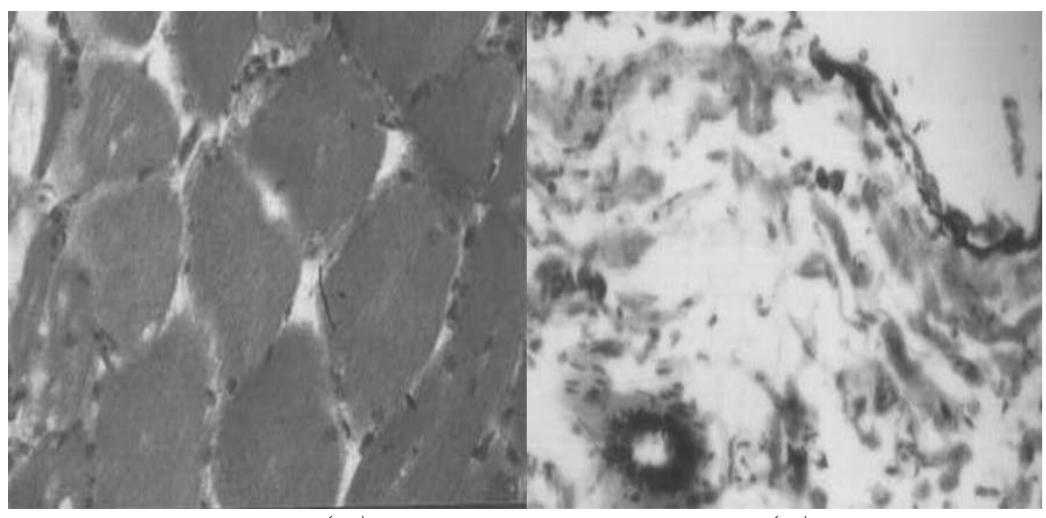

(iii)

(iv)

Figure 5: Effect of chlorpyrifos on tail muscle tissue of D. melanostictus larvae. (i), (iii) Ts and LS of control larvae showing compact myotomes and (ii), (iv) LS and TS of treated larvae showing disintegrated myotomes (Magnification x 400).

Previous studies investigating the effects of pesticides on gill tissues of aquatic organisms report that gills are highly susceptible to damage by such environmental pollutants (e.g. Tommaso, 1986). Gill morphology is therefore considered as a good indicator of the general health of aquatic animals (Peters et al., 1984). In the present study, the gill tissue of larvae exposed to $1500 \mu \mathrm{gl}^{-1}$ of chlorpyrifos had undergone extensive damage, with architectural distortion due to the reduction in the primary and secondary gill lamella, detachment and thickening of its epithelial lining and a marked reduction in the number and size of blood vessels. Oedematous changes were also evident. Similar structural changes in gills have been also shown in the fish Clarias gariepinus when exposed to a glyphosate herbicide (Olurin et al., 2006) and in tadpoles of Scinax nasica as a result of paraquat exposure (Lajmanovich et al., 1998).

Structural aberrations of the gill would no doubt cause serious changes in the respiratory potential of exposed organisms (Kendall and Dale, 1979). Thickening of the epithelial lining increases the distance between water and blood across which oxygen is diffused, ultimately resulting in a reduction in oxygen uptake (Nowak, 1992). A prominent reduction in blood vessels induced by pesticide exposure would restrict blood supply to the gills, also affecting the rate of gaseous exchange. The apparent oedematous changes, observed after two weeks of exposure to chlorpyrifos, in the present study, have been attributed to the increase in capillary permeability (Roberts, 1978), which also affects the normal rate of respiration (Skidmore and Tovell, 1972). Bufonid tadpoles are essentially obligate gill breathers and have rudimentary lungs throughout most of their larval development. In contrast to bufonids, other genera such as Hyla and Rana, have well-developed lungs from an early larval stage. Therefore the tadpoles of the latter genera, unlike in the case of the bufonids, could compensate for the damage caused to gills (Ultsch 
et al., 1999). It is very likely that such alterations in the gill tissue induced by chlorpyrifos at $1500 \mu \mathrm{gl}^{-1}$ may have caused respiratory stress and hence high levels of mortality observed in the tadpoles exposed to chlorpyrifos in the present (Wijesinghe et al., 2011).

The liver, because of its unique metabolic capability, is a prime target of most toxicants (Hopwood et al. 2004). In the case of chlorpyrifos an investigation on rats has suggested that the liver is the main target organ of chlorpyrifos toxicity (Zama et al., 2005). The detoxification process of chlorpyrifos and chlorpyrifos-oxon occurs predominantly in the liver and plasma of animals (ATSDR, 1997; FAO/WHO, 1999), most likely inducing histopathological changes in this organ. Sinusoidal dilatation and congestion in the liver tissue observed in D. melanostictus larvae observed in the present study are very likely caused by the impairment of venous outflow of the hepatic veins (Tanaka and Wanless, 1998). According to Olurin et al. (2006) when the liver is damaged excessive amounts of blood flows into the liver blocking the sinusoids. Thus the blood flow from the hepatic artery and veins into the central vein, and the sinusoids are dialated in order to facilitate this blood flow. Sakr et al. (2001) in a study where catfish Clarias gariepinus were exposed to another organophosphorus insecticide hostathion has made similar observations. Desai et al. (1984) and Kent et al. (1988) have also observed cytoplasmic vacuolation and hyperchromatic nuclei in hepatocytes of the amphibian larvae that were exposed to high concentrations of chlorpyrifos. Vacuolation generally results from degeneration of the cell membrane (Olurin et al., 2006). In the case of the damage to hepatocytes, Michael et al. (1988) state that hepatocytes with hyperchromatic nuclei could be taken as an indication of the exposure of the liver to toxicant-carcinogens. Hepatocytes are the most abundant cell types within the liver and perform most of the liver's essential functions such as the conversion of glucose to glycogen, regulation of lipids and deamination of amino acids (Wright et al., 2004). Structural damage of hepatocytes in response to xenobiotics such as pesticides can result in the impairment of liver function (Hopwood et al., 2004).

The tail muscle tissue of the tadpoles was also subject to histopathological alterations as a result of exposure to chlorpyrifos. Muscle fiber atrophy i.e. the reduction in size and number of myotomes, was the most notable aberration in the present study. These observations comply with those of other studies conducted with organophosphorus insecticides. For instance Xenopus laevis tadpoles exposed to chlorpyrifos and malathion showed complete distortion of myotomes (Bonfantia et al., 2004). They further observed that myocytes were pointed in different directions with no clear cellular boundaries. Hayes (1982) observed necrosis and the swelling and loss of striations of myofibers of rat skeletal muscles after administration of an organophosphate compound. AchE inhibition is the primary mode of toxicity of organophosphorus pesticides and which in tail muscles typically cause repeated firing and hence continuous contraction of tail muscles fibres (Lieu et al., 1997) and thus muscular damage. The atrophy of muscles is also caused by necrosis of muscle fibres, which in mammals is mediated by calcium mobilization (Leonard and Salpeter, 1979). The collapse of the trans-membrane protein complex between myotomes may also have contributed to the loss of connectivity between the myotomes (Peng and Chen, 1992).

Despite the severity of the histopathological damage caused to the gills, liver and tail muscle tissues of the exposed larvae at the end of two weeks of continuous exposure, it was interesting to note that the larvae surviving this exposure did not display extensive damage to the three tissues examined. This could be a result of either recovery from damage or as a result of being resistant to damage, both of which have been shown to occur in amphibians and other aquatic organisms. A study conducted by Honrubia et al., (1993) reports that damage to the gill epithelium and gall-bladder of Rana perezi exposed to a carbamate insecticide was reversed after a few days. Sancho et al. (1997) noted that most of the metabolic disorders in the European eel (Anguilla anguilla) exposed to the organophosphate pesticides fenitrothion, did not persist when allowed to recover in clean water for less than a week. In the present study too tadpoles were kept in clean water for a week after the final exposure. Although potential for recovery has been demonstrated through empirical trials, it has been argued that non-target organisms 
inhabiting aquatic systems associated with agricultural landscapes are often exposed to pesticides for several consecutive months (Gruber and Munn, 1998). In Sri Lanka since a given area typically contains many small paddies, with several local farmers using different application regimes, the shallow streams that drain the paddies repeatedly receive contaminated surface runoff. This being the case, recovery from damage would not be possible under field conditions. The lower degree of damage in tadpoles that have been kept in pesticide-free water for a week might also suggest some degree of resistance. The relative insensitivity of tadpoles to organophosphorus pesticides has been shown by Snawder and Chambers (1989) and is ascribed to either the resilience of AchE (Shapira et al. 1998) or the reduction in glutathione content and the increase in glutathione transferase activity (Anguiano et al., 2001).

\section{Conclusion}

In conclusion the present study which shows that chlorpyrifos induces histopathological responses in important organs such as the gill, liver and muscles in amphibian larvae emphasizes the need to focus on non-lethal effects of continuous exposure of non-target organisms to pesticides. Although the impact on mortality and development are typically used to ascertain the susceptibility of organisms to environmental pollutants, assessing sub-lethal effects such as histological alterations would also be essential to accurately estimate their potential risks on biotic communities.

\section{References}

Adams, S. M., Ham, K. D., Greeley, M. S. LeHew, R. F., Hinton, D. E., and Saylor, C. F. 1996. Downstream gradients in bioindicator responses: Point source contaminant effects on fish health. Canadian Journal of Fisheries and Aquatic Sciences 53: 2177-2187.

Anguiano, O.L., de Castro, A.C., and de D'Angelo, A.M.P. 2001. The role of glutathione conjugation in the regulation of early toad embryos tolerance to pesticides. Comparative Biochemistry and Physiology C 128: 35-43.

ATSDR. 1997. Toxicological profile for chlorpyrifos. Atlanta, Agency for Toxic Substances and Disease Registry.

Bonfanti, P., Colombo, A., Orsi, F., Nizzetto, I., Andrioletti, M., Bacchetta, R., Mantecca, P., Fascio, U., Vailati, G., and Vismara, C. 2004. Comparative teratogenicity of chlorpyrifos and malathion on Xenopus laevis development. Aquatic Toxicology 70: 189-200.

Bridges, C.M. 1997. Tadpole swimming performance and activity affected by acute exposure to sub lethal levels of carbaryl. Environmental Toxicology and Chemistry 16: 1935-1939.

Desai, A.K., Joshi, U.M., and Ambadka, P.M. 1984. Histological observations on the liver of Tilapia mossambica after exposure to monocrotophos, an organophosphorus insecticide. Toxicology Letters 21: 325-331.

FAO/WHO. (1999). Pesticide residues in food. Toxicological evaluations. International Programme on Chemical Safety. Food and Agriculture Organization and World Health Organization.

Gallo-Delgado, S.M., Palacio-Baena, J.A., Gutierrer-C, .P.D.A. 2006. Effects of insecticide chlorpyrifos on growth rate and metamorphosis of Smilisca phaeota (Cope, 1862) (Anura:Hylidae). Actualidades Biologicas 28: 51-58.

Gruber, S.J., Munn, M.D. 1998. Organophosphate and carbamate insecticides in agricultural waters and cholinesterase (ChE) inhibition in common carp (Cyprinus carpio). Archives of Environmental Contamination and Toxicology 35: 391-396.

Hayes, W.J.J. 1982. Organic phosphorus pesticides. In: Pesticides studied in man. Baltimore, Williams and Wilkins. p.294.

Hibiya, T. 1982. An Atlas of fish histology. Normal and pathological features. Kodansha Ltd., Tokyo. 
Honrubia, M.P., Paz Herráez, M., and Alvarez, R. 1993. The carbamate insecticide ZZ-Aphox ${ }^{\circledR}$ induced structural changes of gills, liver, gall bladder, heart, and notochord of Rana perezi tadpoles. Archives of Environmental Contamination and Toxicology 25: 184-191.

Hopwood, J., Quigley, A., Eagle, C., Powell, H., Eakins, J., and Kenna, G.U.K, 2004. Are primary rat hepatocyte cultures appropriate for predictive hepato toxicity testing of pharmaceuticals? Toxicology 202, 33-127.

IUCN 2007. The 2007 Red list of threatened fauna and flora of Sri Lanka. Colombo, International Union for Conservation of Nature, Sri Lanka.

Kamrin, M.A. 1997. Pesticides profiles toxicity, environmental impact and fate. New York.

Kendall, M.W., Dale, J.E. 1979. Scanning and transmission electron microscope observations of rainbow trout gill. Journal of Fisheries Research Board Canada. 36, 1072-1079.

Kent, M.L., Myers, M.S., Hinton, D.E., Eaton, W.D., and Elston, R.A. 1988. Suspected toxicopathic hepatic necrosis and megalocytosis in pen-reared Atlantic salmon Salmo salar in Puget Sound, Washington, USA. Diseases of Aquatic Organisms 4: 91-100.

Kirtisinghe, P. 1955. The Amphibian of Ceylon $.1^{\text {st }}$ edition. Charles Circus, Colombo.

Lajmanovich, R.C., Izaguirre, M.F., and Casco, V.H. 1998. Paraquat tolerance and alteration of internal gill structure of Scinax nasica tadpoles (Anura: Hylidae). Archives of Environmental Contamination and Toxicology 34: 364-369.

Leonard, J.P. and Salpeter, M.M. 1979. Agonost-induced myopathy at the neuromuscular junction is mediated by calcium. Journal of Cell Biology 82: 811-819.

Lien, N.T., Adriaens, D., and Janssen, C.R. 1997. Morphological abnormalities in African cat fish (Clarius gariepirus) larvae exposed to malathion. Chemosphere. 35: 1475-1486.

Michael, L., Kent, M.S., Myers, D E., Hinton, W.D., and Eaton, R.A. 1988. Suspected toxicopathic hepatic necrosis and megalocytosis in pen-reared Atlantic salmon Salmo salar in Puget Sound, Washington, USA. Diseases of Aquatic Organisms 4: 91-100.

Miles, J.R.W., Harris, C.R., and Tu, C.M. 1983. Influence of temperature on the persistence of chlorpyrifos and chlorfenvinphos in sterile and natural mineral and organic soils Journal of Environmental Science and Health Part B Pesticides Food Contaminants and Agricultural Wastes 18: 705-712.

Neskovic, N.K., Poleksic, V., Elezovic, I., Karan, V., and Budimir, M. 1996. Biochemical and histopathological effects of glyphosate on carp, Cyprinus carpio L. Bulletin of Environmental Contamination and Toxicology 56: 295-302.

Nowak, B. 1992. Histological changes in gills induced by residues of endosulfan. Aquatic Toxicology 23: $65-84$.

Olurin, K.B., Olojo, E.A.A.1., Mbaka, G.O., and Akindele, A.T.1. 2006. Histopathological responses of the gill and liver tissues of Clarias gariepinus fingerlings to the herbicide, glyphosate. African Journal of Biotechnology 5: 2480-2487.

Peters, G., Hoffmann, R., and Klinger, H. 1984. Environmental induced gill disease of cultured rainbow trout (Salmo gairdner). Aquaculture 38: 105-126.

Pethiyagoda, R., and Manamendra-Archchi, K. 2006. Sri Lankan Amphibians: Diversity, uniqueness and conservation. In: C. N. B. Bambaradeniya (ed). The Fauna of Sri Lanka, World Conservation Union, Colombo, Sri Lanka.

Peng, H.B., and Chen, Q. 1992. Induction of dystrophin localization in cu;tured Xenopus muscle cells by latex beads. Journal of Cell Science 103: 551-563.

Roberts, R.J. 1978. Fish pathology. Baillierre Tindall, London.

Rouse, J.D., Bishop, C.A., and Struger, J. 1999. Nitrogen Pollution: An assessment of its threat to amphibian survival. Environmental Health Perspectives 107: 799-803. 
Rousseaux, C.G., Branchaud, A., and Spear, P.A. 1995. Evaluation of liver histopathalogy in St. Lawrence lake sturgeon (Acipenser fulvescens) in comparison with a reference population. Environmental Toxicology and Chemistry 14: 843-849.

Sakr S .A., Hanafy, S.M., and El-Desouky, N.E. 2001. Histopathological, histochemical and physiological studies on the effect of the insecticide, Hostathion on the liver of the catfish Clarias gariepinus. Egyptian Journal Aquatic Biology and Fisheries 6: 103-124.

Sancho, E., Ferrando, M.D., and Andreu, E. 1997. Sublethal effects of an organophosphate insecticide on the European eel, Anguilla Anguilla. Ecotoxicology and Environmental Safety 36: 57-65.

Shapira, M., Seidman, S., Livni, N., and Soreq, H. 1998. In vivo and in vitro resistance to multiple anticholinesterase in Xenopus laevis tadpoles. Toxicology Letters 28: 205-209.

Skidmore, J.F., and Tovell, P.W.A. 1972. Toxic effects of zinc sulphate on the gills of rainbow trout. Water Research 6: 217-30.

Snawder, J.E., and Chambers, J.E. 1989. Toxic and developmental effects of organophosphorus insecticides in embryos of the South African clawed frog. Journal of Environmental Science and Health 24: 205-218.

Sumanadasa, D.M., Wijesinghe, M.R., and Ratnasooriya, W.D. 2008. Effects of Diazinon on larvae of the Asian Common Toad (Bufo melanostictus Schneider 1799). Environmental Toxicology and Chemistry 27: 157-162.

Tanaka, M., and Wanless, I.R. 1998. Pathology of the liver in Budd-Chiari syndrome: portal vein thrombosis and the histogenesis of veno-centric cirrhosis, veno-portal cirrhosis, and large regenerative nodules. Herpetology 27: 488-496.

Tommaso, T.R. 1986. Comparative toxicity of nitrate in fresh water fish. Aquatic Toxicology 8: 129-137.

Ultsch, G.R., Bradford, D.F., and Freda, J. 1999. Physiology: coping with the environment. University of Chicago Press, Chicago.

Wijesinghe, M. R., Bandara, M.G.D.K., Ratnasooriya, W. D. and Lakraj, G. P. 2011. Chlorpyrifosinduced toxicity in Duttaphrynus melanostictus Schneider 1799 larvae. Archives of Environmental Contamination and Toxicology, 60: 690-696.

Wright, M.C., Mann, D.A., Orr1, J.G., Hawksworth1, G.M., Marek1, C.J., Leel, V., Haughton, E.L., Koruth, M., Murray, G.I., Trim, J.E., and Elrick, L.J. 2004. Intercellular signaling by cytokines and the fibrogenic response of the liver to chronic liver damage. Toxicology 202: 33-127.

Young, B.E., Lips, K.R., Reaser, J.K., Ibanez, R., Salas, A.W., Cedeno, J.R., Coloma, L.A., Ron, S., Marca, E.La., Meyer, J R., Munoz, A., Bolanos, F., Chaves, G., and Romo, D. 2001. Population declines and priorities for amphibian conservation in Latin America. Conservation Biology 15: 12131223.

Zama, D., Meraihi, Z., Boubekri, N., Amrani, A., Tebibel, S., and Baali, N. 2005. Assessment of the changes in some diagnostic enzymes and other parameters in Wistar albino rats treated with pesticides during gestation. .Algeria Sciences and Technologies 23: 51-56. 